\title{
The influence of pre-exercise glucose ingestion on endurance running capacity
}

\author{
Costas Chryssanthopoulos, Liam C. M. Hennessy and Clyde Williams \\ Department of Physical Education, Sports Science and Recreation Management, Loughborough University, \\ Loughborough, UK
}

\begin{abstract}
Drinking a concentrated glucose solution less than $1 \mathrm{~h}$ before the start of prolonged submaximal exercise has been reported to reduce endurance capacity during cycling. The purpose of this study was to re-examine the influence of pre-exercise ingestion of a concentrated glucose solution on endurance running capacity. Nine recreational runners (five men and four women) ran to exhaustion on a level treadmill, at speeds equivalent to $70 \% \dot{V O}_{2 \max }$, on two occasions separated by at least 1 week. The runners ingested either a solution containing $75 \mathrm{~g}$ of glucose in $300 \mathrm{ml}$ of water (G trial), or $300 \mathrm{ml}$ of sweetened water ( $P$ trial) $30 \mathrm{~min}$ before each trial. As a consequence, the blood glucose concentrations were $55 \%$ higher at the beginning of the $G$ trial compared with those recorded for the $P$ trial (G trial, mean(s.e.) blood glucose = 6.3(0.7) $\mathrm{mmol}^{-1}$ versus $P$ trial, mean(s.e.) blood glucose = 4.1(0.3) $\left.\mathrm{mmol}^{-1} ; P<0.01\right)$. Nevertheless, there were no differences in the running times to exhaustion between the two trials (G trial, mean(s.e.) 133.79(11.0) min versus $P$ trial, mean(s.e.) 121.16(8.1) min). The results of this study show that ingesting a $25 \%$ glucose solution $30 \mathrm{~min}$ before exercise does not reduce the endurance capacity of recreational runners when the exercise intensity is equivalent to $70 \% \dot{V}_{\mathrm{O}_{2} \max }$.
\end{abstract}

Keywords: Glucose ingestion, blood glucose, running capacity

Fatigue during prolonged exercise of submaximal intensity occurs when muscle glycogen stores are reduced to critically low concentrations $s^{1,2}$. It is not surprising, therefore, that there has been considerable attention given to methods of increasing the limited muscle glycogen stores in preparation for endurance races ${ }^{3}$. Although there is evidence to show that consuming carbohydrate foods $3-4 \mathrm{~h}$ before exercise improves exercise capacity, ${ }^{4,5}$, there is a widely held view that consuming any carbohydrates within the hour before exercise decreases exercise capacity 6 .

Address for correspondence: Professor C. Williams, Department of Physical Education, Sports Science and Recreation Management, Loughborough University, Loughborough, Leicestershire LE11 3TU, UK

(C) 1994 Butterworth-Heinemann Ltd 0306-3674/94/020105-05
There are only two studies which provide substantial evidence for this view ${ }^{7,8}$. Costill and colleagues reported that the ingestion of a concentrated glucose solution $45 \mathrm{~min}$ before the start of submaximal treadmill running caused a greater rate of muscle glycogen utilization than when exercise was performed after drinking water. This increased rate of glycogenolysis would, it was proposed, lead to an early onset of fatigue during prolonged exercise. Foster and colleagues ${ }^{8}$ confirmed this hypothesis in a study which showed that cycling time to exhaustion was reduced by $19 \%$ when their subjects ingested a $25 \%$ glucose solution $30 \mathrm{~min}$ before exercise. Muscle glycogen concentrations were not measured but the study did show an elevation in serum insulin and a reduction in serum fatty acid concentrations ${ }^{8}$. The cause of the early onset of fatigue was, according to the authors, a decrease in the availability of serum fatty acids for muscle metabolism which, in turn, increased the rate of muscle glycogen depletion and caused the early onset of fatigue?

Therefore, the explanation offered by Foster and colleagues $^{8}$ for the paradoxical onset of fatigue following the pre-exercise ingestion of a concentrated glucose solution is, in theory, sound. But closer examination of the results of their study leaves several questions unanswered. For example, the rates of carbohydrate oxidation were the same during the glucose and water trials. If there had been an increased rate of glycogenolysis then this latter result is difficult to explain. Furthermore, there were no differences in perceived rates of exertion recorded during the two trials and yet their cyclists exercised for $10 \mathrm{~min}$ less on the glucose trial.

More recently, however, Fielding et al. ${ }^{10}$ showed that the pre-exercise ingestion of fructose and glucose solutions had no greater influence on the rate of muscle glycogen utilization during exercise than the pre-exercise ingestion of water. McMurray et al. ${ }^{11}$ provided some evidence to show that the pre-exercise ingestion of either glucose or fructose solutions by female runners, before exercise, has no detrimental influence on running performance. The exercise duration in this latter study was only approximately $60 \mathrm{~min}$, probably because of the high exercise intensity $\left(80 \% \dot{V}_{\mathrm{O}_{2} \text { max }}\right)$ which in turn resulted in blood lactate concentrations of about $5 \mathrm{mmol}) \mathrm{l}^{-1}$ at 
exhaustion $^{11}$. Nevertheless, the exercise intensity and duration were similar, in this running study, to those used by Foster et al. ${ }^{8}$ in their cycling study. Lower exercise intensities are normally chosen during races over long distances, presenting a greater challenge to muscle glycogen stores rather than the capacity of muscle to buffer the hydrogen ions associated with lactic acid accumulation.

Therefore, the purpose of the present study was to re-examine the influence of ingesting a $25 \%$ glucose solution $30 \mathrm{~min}$ before exercise on endurance running capacity, at an exercise intensity $\left(70 \% \dot{V}_{\mathrm{O}_{2} \max }\right)$ which is more appropriate for endurance races.

\section{Subjects and methods}

Five men and four women volunteered to take part in the study. The mean(s.e.) age, weight and maximal oxygen uptake were $24.5(1.4)$ years, $63.8(1.6) \mathrm{kg}$, and $54.3(2.5) \mathrm{ml} \mathrm{kg}^{-1} \mathrm{~min}^{-1}$ for the women and $22.4(1.3)$ years, $76.4(2.7) \mathrm{kg}$, and $67.0(3.0) \mathrm{ml} \mathrm{kg}^{-1} \mathrm{~min}^{-1}$ for the men. All subjects were fully informed of the nature and purpose of the study before giving formal consent and were aware that they could withdraw from the study at any time without disclosing their reasons. The study was conducted in accordance with the guidelines laid down by the University's Ethical Advisory Committee.

\section{Experimental design}

The study consisted of two runs to exhaustion at $70 \%$ $\dot{V}_{\mathrm{O}_{2} \max }$ on a motorized level treadmill (Quinton, Seattle, USA). Subjects performed the two trials with at least 1 week between. They reported to the laboratory after an overnight fast. Each subject, $30 \mathrm{~min}$ before exercise, ingested either $200 \mathrm{ml}$ of water together with $100 \mathrm{ml}$ of an artificially sweetened placebo solution $(\mathrm{P})$, or $75 \mathrm{~g}$ of glucose dissolved in $200 \mathrm{ml}$ of water together with the $100 \mathrm{ml}$ of the artificially sweetened placebo solution (G). The administration of the solutions was randomly assigned under double blind conditions.

The subjects were encouraged to run for as long as possible. However, when they were unable to maintain their prescribed running speed, and in order to ensure exhaustion, subjects were allowed to reduce the speed once for $2 \mathrm{~min}$. The time at which subjects were allowed to reduce the speed was defined as volitional fatigue (F1). Thereafter, the speed was returned to the prescribed speed and the subjects encouraged to continue running for as long as possible. The time to volitional fatigue (F1) and to exhaustion (Exh) were recorded for each subject during both trials. Water was freely available for the subjects to drink ad libitum throughout both trials. The total amount of water consumed (W) by each subject was, however, monitored and recorded. Heart rate (HR) was monitored continuously throughout exercise using a heart rate monitor (Rigel, model 302; Rigel Research, Morden, UK) connected to the subject via four chest electrodes.

\section{Blood sampling and analyses}

Duplicated capillary blood samples $(20 \mu \mathrm{l})$, from the thumb of each subject, were obtained before the ingestion of the solutions, immediately before the start of exercise, every 15 min during the first hour of exercise, every $30 \mathrm{~min}$ thereafter and at exhaustion (Exh). Samples were frozen after being deproteinized in $200 \mu \mathrm{l}$ of $2.5 \%$ perchloric acid, stored at $-20^{\circ} \mathrm{C}$ and later analysed for glucose (Colorimeter; Jenway, Essex, UK), using a commercially available kit (Boehringer Mannheim Diagnostica; Lewes, UK), and lactate (Perkin-Elmer $1000 \mathrm{~m}$ fluorimeter; PerkinElmer, Beaconsfield, UK) according to the method described by Maughan ${ }^{12}$.

\section{Measurement of gas exchange}

During each trial expired air was collected every 15 min during exercise as well as at Exh using the Douglas bag method. Oxygen was analysed using a paramagnetic oxygen analyser (Sybron/Taylor 570A, Servomex, Crowborough, UK) and carbon dioxide content was determined using an infrared analyser (Lira 3000, MSA, East Shawhead, Coatbridge, Scotland). A dry gas meter (Harvard Apparatus, Edenbridge, UK) calibrated against a 600 I Tissot Spirometer (Collins, Braintree, Massachusetts, USA) was used to measure the volume of expired air. Before each analysis, instruments were calibrated against known gas mixtures. During the expired air collections, the runners' perceived rate of exertion (PRE) was recorded ${ }^{13}$.

\section{Nutritional status}

The subjects recorded their food intakes for the 2 days before their first trial and ate the same amount and range of foods during the 2 days before their second trial. They also undertook about the same amount of physical activity during the 2 days before each trial and refrained from heavy training.

\section{Preliminary measurements}

The $\dot{V}_{\mathrm{O}_{2} \text { max }}$ of each subject was determined during an uphill treadmill running test ${ }^{14}$ and on a subsequent occasion the oxygen cost $\left(\dot{V}_{\mathrm{O}_{2}}\right)$ of running over a range of submaximal running speeds was also determined $^{15}$. From this information the running speed required to elicit $70 \%$ of each subject's $\dot{V}_{\mathrm{O}_{2} \max }$ was predicted. Finally, before the two runs to exhaustion and on a separate occasion, the subjects undertook a 10 -min treadmill run at speeds predicted to be equivalent to $70 \% \dot{V}_{\mathrm{O}_{2} \max }$ in order to confirm their relative exercise intensity $\left(70 \% \quad \dot{V}_{\mathrm{O}_{2} \text { max }}\right)$. The mean(s.e.) temperatures and relativity humidities in the laboratory during the $\mathrm{G}$ and $\mathrm{P}$ trials were $21.8(0.6)^{\circ} \mathrm{C} ; 44 \%$ and $22.3(0.9)^{\circ} \mathrm{C} ; 51 \%$ respectively.

\section{Statistical analysis}

The results from each trial were compared using two-tailed paired $t$ tests for correlated data as outlined by Cohen and Holliday ${ }^{16}$. The accepted level of significance was set at $P=0.05$. Data are reported as means(s.e.). 


\section{Results}

There were no differences in mean(s.e.) exercise times to $\mathrm{F} 1$ ( $\mathrm{P}$ trial, 105.38(7.42) min versus $\mathrm{G}$ trial, 119.52(12.02) min; $P=0.16$ ) nor in the times to Exh ( $P$ trial, 121.16(8.1) min versus G trial, $133.79(11.0) \mathrm{min} ; P$ $=0.08$ ). However, seven of the nine subjects ran for longer during the $G$ trial than during the $P$ trial. Furthermore, no order effect was found for running times to exhaustion for the first and second trials.

Mean(s.e.) blood glucose concentration was higher $(P<0.01)$ immediately before the start of exercise in the $G$ trial $\left(6.3(0.7) \mathrm{mmoll}^{-1}\right)$ than at the same time during the $\mathrm{P}$ trial $\left(4.1(0.3) \mathrm{mmoll}^{-1}\right)$. When the results of one subject, who experienced glucose intolerance, are omitted, then the mean blood glucose concentrations at $15 \mathrm{~min}$ and $30 \mathrm{~min}$ during the $\mathrm{G}$ trial are lower $(P<0.01)$ than the values obtained, at the same sampling times, during the $\mathrm{P}$ trial (Figure 1). However, after the first $30 \mathrm{~min}$ of exercise, the mean blood glucose concentrations in both trials remained above $4 \mathrm{mmol}^{-1}$. At exhaustion, the blood glucose concentrations were similar in both trials.

Blood lactate concentrations were also similar during the two trials with mean(s.e.) values of $3.5(0.4) \mathrm{mmol}^{-1}$ and 3.3(0.5) $\mathrm{mmol}^{-1}$ for the $\mathrm{G}$ and $P$ trials respectively (Figure 2 ).

There was no overall difference in $R$ values between the two trials (Table 1), even though the mean(s.e.) $R$ value at exhaustion during the $G$ trial appears to be lower than the value obtained at the end of the $P$ trial ( $G$ trial $0.86(0.03)$ versus $P$ trial, $0.90(0.01) ; P>0.05)$. The mean(s.e.) energy cost $(P$ trial, $61.0(4.3) \mathrm{kJ} \mathrm{min}^{-1}$ versus $\mathrm{G}$ trial, $61.5(4.0$

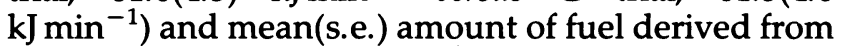
fat $\left(\mathrm{P}\right.$ trial, $0.5(0.1) \mathrm{g} \mathrm{min}^{-1}$ versus $\mathrm{G}$ trial $0.6(0.1)$ $\mathrm{g} \mathrm{min}^{-1}$ and mean(s.e.) carbohydrates ( $\mathrm{P}$ trial, 2.5(0.3) $\mathrm{g} \mathrm{min}^{-1}$ versus $\mathrm{G}$ trial, 2.3(0.3) $\mathrm{g} \mathrm{min}^{-1}$ ) calculated using a non-protein $R$ were similar during the two conditions.

There were no differences between mean(s.e.) oxygen uptake, heart rate, perceived rate of exertion

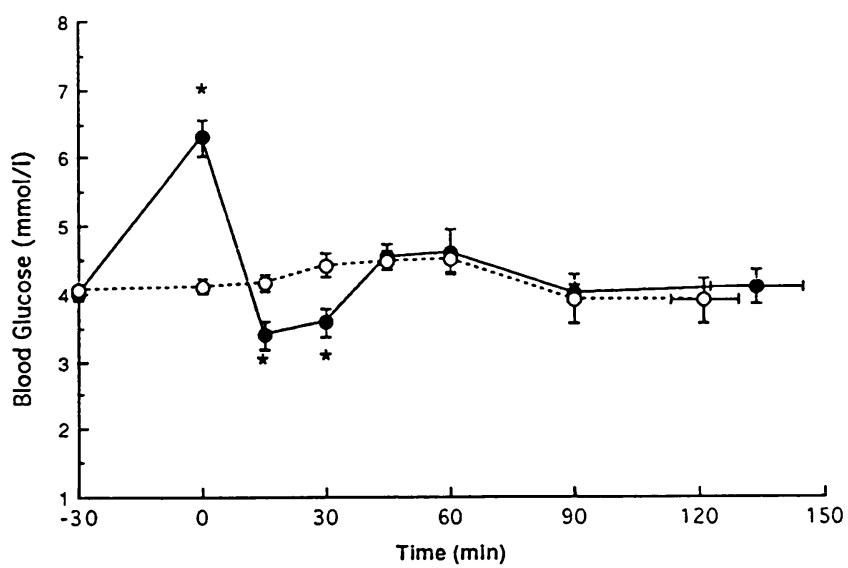

Figure 1. Blood glucose concentration during the glucose $(G, O)$ and the placebo $(P, O)$ trials (mean(s.e.), $n=8)$; *Significantly different from $\mathrm{P}(P<0.01)$

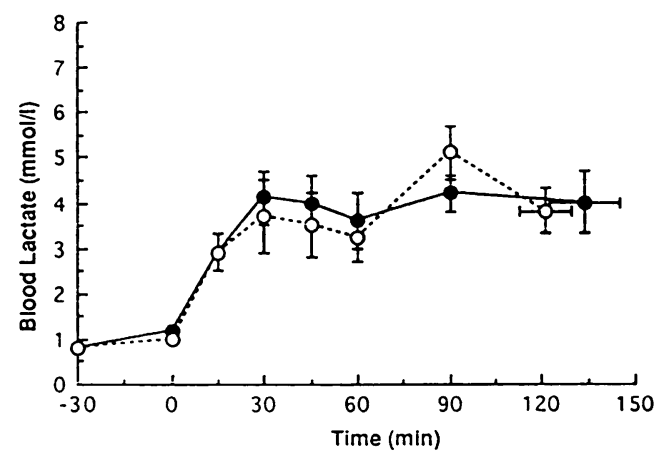

Figure 2. Blood lactate concentrations during the glucose $(G, O)$ and the placebo $(P, \bigcirc)$ trials (mean(s.e.))

values (Table 1), nor water intake ( $\mathrm{P}$ trial, 211.6(46.2) $\mathrm{ml} \mathrm{h}^{-1}$ versus $\mathrm{G}$ trial, $\left.187(42.3) \mathrm{ml} \mathrm{h}^{-1}\right)$, or weight loss ( $\mathrm{G}$ trial, 2.65(0.27) $\mathrm{kg}$ versus $\mathrm{P}$ trial, $2.47(0.18) \mathrm{kg}$ ) during the two trials.

There were no differences in the mean(s.e.) energy intakes of the runners before each trial (G trial, 9.1(1.1) MJ versus $P$ trial, 9.1(1.5) $M J)$ nor in the mean(s.e.) daily carbohydrate intake before each trial ( $G$ trial, 324.6(36) g versus P trial, 306.3(26) g).

Table 1. Respiratory exchange ratio, oxygen uptake, perceived rate of exertion (PRE) and heart rate (HR) during glucose (G) and placebo $(P)$ trials

\begin{tabular}{|c|c|c|c|c|c|c|c|}
\hline & \multicolumn{7}{|c|}{ Time $(\min )$} \\
\hline & 15 & 30 & 45 & 60 & 75 & 90 & Exh \\
\hline \multicolumn{8}{|c|}{ Respiratory exchange ratio (R) } \\
\hline G & $0.90(0.01)$ & $0.90(0.02)$ & $0.89(0.01)$ & $0.89(0.02)$ & $0.90(0.02)$ & $0.89(C .02)$ & $0.86(0.03)$ \\
\hline $\mathbf{P}$ & $0.91(0.01)$ & $0.90(0.01)$ & $0.90(0.01)$ & $0.89(0.01)$ & $0.90(0.01)$ & $0.90(0.01)$ & $0.90(0.01)$ \\
\hline \multicolumn{8}{|c|}{$V_{O_{2}}\left(m / k g^{-1} \min ^{-1}\right)$} \\
\hline G & $42.8(2.1)$ & $43.2(2.1)$ & 43.1(2.0) & $43.6(2.1)$ & $43.5(2.0)$ & $43.9(2.0)$ & $45.2(2.2)$ \\
\hline $\mathbf{P}$ & $42.7(1.8)$ & $43.2(2.0)$ & $42.8(2.1)$ & $43.5(2.1)$ & $43.6(2.2)$ & $43.5(2.1)$ & $44.8(2.1)$ \\
\hline \multicolumn{8}{|l|}{ PRE } \\
\hline G & $10(0.5)$ & $11(0.3)$ & $12(0.2)$ & $13(0.3)$ & $13(0.3)$ & $14(0.6)$ & $17(0.7)$ \\
\hline $\mathbf{P}$ & $10(0.2)$ & $11(0.1)$ & $12(0.2)$ & $13(0.3)$ & $14(0.5)$ & $15(0.6)$ & $18(0.7)$ \\
\hline \multicolumn{8}{|c|}{$H R$ (beats $\min ^{-1}$ ) } \\
\hline G & 156(3) & $161(4)$ & $164(3)$ & $167(2)$ & $172(2)$ & $168(2)$ & 171(2) \\
\hline $\mathbf{P}$ & $152(3)$ & $158(3)$ & $162(3)$ & $165(3)$ & $164(3)$ & $166(3)$ & $167(3)$ \\
\hline
\end{tabular}

Values are mean(s.e.) 


\section{Discussion}

The main finding of this study was that there was no difference in the running times to exhaustion between the two trials. Even though there was a rapid fall in blood glucose concentration during the first 30 min of running, in the $G$ trial, exercise times to F1 and Exh were no different than the values obtained for the $P$ trial. In fact, seven of the nine subjects performed better during the $G$ trial than during the $P$ trial. Their overall running times to exhaustion were approximately $10.4 \%$ longer than in the $P$ trial $(P=0.08)$.

In general, the ingestion of glucose solutions before exercise improves endurance capacity as reported by Gleeson et al. ${ }^{17}(+13.4 \%)$, by Maughan and Gleeson ${ }^{18}$ $\left(+19 \%\right.$, after $36-\mathrm{h}$ fast) and by Peden et al. ${ }^{19}$ in power output during the last $45 \mathrm{~min}$ of exercise $(+12-13 \%)$.

Although the improvement in performance found in the present study was not statistically significant, the results are consistent with those reported by other authors that pre-exercise feedings with either glucose $^{17,18,20,21}$, or solid carbohydrates ${ }^{21-23}$ do not produce an earlier onset of fatigue than during exercise without prior glucose ingestion. For example, after cycle ergometer exercise to exhaustion, no differences in muscle glycogen depletion or in exercise time to exhaustion were found for subjects who had consumed either solid or liquid carbohydrates or a sweet placebo before exercise ${ }^{21,22}$.

Only two studies, however, have reported negative effects on performance, as a result of pre-exercise ingestion of a glucose solution ${ }^{8,24}$. Keller and Schwarzkopf ${ }^{24}$ reported that their subjects were exhausted after about $19 \mathrm{~min}$ and $25 \mathrm{~min}$ of intermittent cycle exercise during glucose and placebo trials respectively. These endurance times are short compared with the ones usually reported by other investigators. They were probably the consequence of the high exercise intensity $\left(85 \% \dot{V}_{\mathrm{O}_{2} \text { max }}\right)$, and the low pre-exercise muscle glycogen concentrations. In the study reported by Foster and colleagues ${ }^{8}$, pre-exercise ingestion of a $25 \%$ glucose solution reduced exercise time to exhaustion by $19 \%$ when their subjects cycled at an exercise intensity equivalent to $84 \% \dot{V O}_{2 \text { max }}$. Furthermore, more recently, Fielding et al. ${ }^{10}$ replicated the study of Costill et al. ${ }^{7}$ with well-trained runners. They found that the pre-exercise ingestion of glucose and fructose solutions did not produce a greater utilization of muscle glycogen than the pre-exercise ingestion of water ${ }^{10}$.

Although plasma free fatty acids (FFA) and muscle glycogen concentrations were not measured in the present study, the mean(s.e.) oxidation rates, as calculated from $R$ values, of carbohydrate (G trial, 2.3(0.3) $\mathrm{g} \mathrm{min}^{-1}$ versus $P$ trial, 2.5(0.3) $\mathrm{g} \mathrm{min}^{-1}$ ) and fat (G trial, 0.6(0.1) $\mathrm{g} \mathrm{min}^{-1}$ versus $\mathrm{P}$ trial, 0.5(0.04) $\mathrm{g} \mathrm{min}^{-1}$ ) were similar during both trials. The fact that the majority of subjects ran for longer during the $G$ trial also casts doubt on the suggestion that preexercise ingestion of a concentrated glucose solution accelerates the onset of fatigue as a consequence of a higher rate of glycogenolysis.
The decrease in blood glucose concentration during the first $30 \mathrm{~min}$ of exercise of the $\mathrm{G}$ trial in the present study (Figure 1) is similar to the responses reported by other investigators $7,8,10,11,25$. This decrease in blood glucose concentration may be the consequence of an increased uptake of glucose by muscle in the presence of an increased plasma insulin concentration. The inability of liver glycogen to replace blood glucose at the same rate as muscle takes up this substrate may lead to hypoglycaemia ${ }^{26,27,28}$. Nevertheless, blood glucose concentration returned to pre-exercise levels after $45 \mathrm{~min}$ of exercise in the $G$ trial, which is a response which is similar to findings in other studies $11,19,22,28$.

Felig et al. $^{29}$ suggested that during prolonged exercise, hypoglycaemia per se does not cause fatigue and its prevention does not delay exhaustion. In the present study blood glucose concentrations were over $4 \mathrm{mmol}^{-1}$ at exhaustion during both the $G$ and $P$ trials and so fatigue was not the result of hypoglycaemia. It may be of interest to note, however, that one subject developed the subjective symptoms of hypoglycaemia towards the end of the $\mathrm{P}$ trial. His blood glucose concentration decreased to $2.3 \mathrm{mmol}^{-1}$. In contrast, during the $\mathrm{G}$ trial the blood glucose concentrations were higher for this subject and even at exhaustion achieved a value of $3.4 \mathrm{mmol} \mathrm{l}^{-1}$.

It may be argued that there are some people who are sensitive to a low blood glucose concentration and for them exercise induced hypoglycaemia may be a major factor contributing to fatigue. Coyle et al. ${ }^{30}$ reported a $26 \%$ improvement in cycling time to fatigue with carbohydrate feeding in seven subjects in whom blood glucose decreased during the control (placebo) condition. Subjects who had no significant decrease in blood glucose concentration during the placebo trial did not improve their endurance capacity as a result of carbohydrate feeding during exercise $^{30}$. It seems that glucose intake during exercise maintains euglycaemia and delays fatigue either by reducing the rate of muscle glycogen utilization ${ }^{31}$ or by providing carbohydrates for oxidation during the later stages of exercise ${ }^{32}$.

Intestinal distress has been reported during treadmill running after pre-exercise glucose ${ }^{11}$, or fructose, ingestion ${ }^{28}$. Although fructose feeding may produce gastrointestinal discomfort due possibly to its slower rate of absorption from the small intestine ${ }^{28}$, it is difficult to explain the cause of gastrointestinal distress experienced by two subjects in $G$ trial and two subjects in $P$ trial in this study. It would seem that the carbohydrate content of the pre-exercise drink did not promote such problems to any greater degree than the placebo solution. One may argue, however, that during weight bearing activities, such as running, the capacity for fluid ingestion is less than can be tolerated during cycling ${ }^{33}$. In fact, fluid intake by runners during competitions is smaller than the prescribed volumes of fluid consumed in laboratory studies ${ }^{34}$. This is confirmed in the present study in which only small amounts of fluid were ingested by the runners in the two trials ( $\mathrm{G}$ trial, $187.1 \mathrm{ml} \mathrm{h}^{-1}$ versus $\mathrm{P}$ trial, $211.6 \mathrm{ml} \mathrm{h}^{-1}$ ). 
In conclusion, the findings of this study show that despite the transient decrease in blood glucose concentration during the first $30 \mathrm{~min}$ of exercise, pre-exercise glucose ingestion does not reduce treadmill running time to exhaustion.

\section{Acknowledgements}

The authors would like to thank Dr G. Gaitanos for his help in the preparation and administration of the glucose and placebo solutions.

\section{References}

1 Hermansen L, Hultman E, Saltin B. Muscle glycogen during prolonged severe exercise. Acta Physiol Scand 1967; 71: 120-39.

2 Karlsson J, Saltin B. Diet, muscle glycogen and endurance performance. I Appl Physiol 1971; 31: 203-6.

3 Sherman WM, Costill DL, Fink W, Miller J. Effect of exercise-diet manipulation on muscle glycogen and its subsequent utilization during performance. Int J Sports Med 1981; 2: 114-18.

4 Neufer DP, Costill DL, Flynn MG, Kirwan JP, Mitchell JB, Houmard J. Improvements in exercise performance: effects of carbohydrate feedings and diet. J Appl Physiol 1987; 62: 983-8.

5 Wright DA, Sherman WM, Dernbach AR. Carbohydrate feedings before, during, or in combination improve cycling performance. J Appl Physiol 1991; 71: 1082-8.

6 Wootton SA. Nutrition for Sport. London, UK: Simon and Schuster 1989: 159.

7 Costill DL, Coyle E, Dalsky G, Evans W, Fink W, Hoopes D. Effects of elevated plasma FFA and insulin on muscle glycogen usage during exercise. J Appl Physiol 1977; 43: 695-9.

8 Foster C, Costill DL, Fink WJ. Effects of preexercise feedings on endurance performance. Med Sci Sports Exerc 1979; 11: 1-5.

9 Pernow B, Saltin B. Availability of substrates and capacity for prolonged heavy exercise in man. J Appl Physiol 1971; 31: 416-2.

10 Fielding RA, Costill DL, Fink WJ, King DS, Kovaleski JE, Kirwan JP. Effects of pre-exercise carbohydrate feedings on muscle glycogen use during exercise in well-trained runners. Eur J Appl Physiol 1987; 56: 225-9.

11 McMurray RG, Wilson JR, Kitchell BS. The effects of fructose and glucose on high intensity endurance performance. Res Quart Exerc Sport 1983; 54: 156-62.

12 Maughan RJ. A simple rapid method for the determination of glucose, lactate, pyruvate, alanine, 3-hydroxybutyrate and acetoacetate on a single $20 \mu \mathrm{l}$ blood sample. Clin Chem Acta 1982; 122: 231-40.

13 Borg GAV. Perceived exertion: a note on 'history' and methods. Med Sci Sports Exerc 1973; 5: 90-3.

14 Taylor HL, Buskirk E, Henschel A. Maximal oxygen intake as an objective measure of cardio-respiratory performance. $J$ Appl Physiol 1955; 8: 73-80.

15 Williams C, Nute MLG. Some physiological demands of half-marathon race on recreational runners. $\mathrm{Br} J$ Sports Med 1983; 17: 152-61.
16 Cohen L, Holliday M. Statistics for Social Scientists. London, UK: Harper and Row, 1982.

17 Gleeson M, Maughan RJ, Greenhaff P. Comparison of the effects of pre-exercise feeding of glucose, glycerol and placebo on performance and fuel homeostasis in man. Eur J Appl Physiol 1986; 55: 645-53.

18 Maughan RJ, Gleeson M. Influence of a $36 \mathrm{~h}$ fast followed by refeeding with glucose, glycerol or placebo on metabolism and performance during prolonged exercise in man. Eur Appl Physiol 1988; 57: 570-76.

19 Peden C, Sherman WM, D'Aquisto L, Wright DA. $1 \mathrm{H}$ preexercise carbohydrate meals enhance performance. Med Sci Sports Exerc 1989; 21: S59.

20 Bonen A, Malcolm SA, Kilgour RD, MacIntyre KP, Belcastro AN. Glucose ingestion before and during exercise. I Appl Physiol 1981; 50: 766-71.

21 Devlin JT, Calles-Escandon J, Horton ES. Effects of preexercise snack feeding on endurance cycle exercise. I Appl Physiol 1986; 60: 980-85.

22 Alberici JC, Farrell PA, Kris-Etherton PM, Shively CA. Effects of preexercise candy bar ingestion on substrate utilization and performance in trained cyclists. Med Sci Sports Exerc 1989; 21: S47.

23 Calles-Escandon J, Devlin JT, Whitcomb W, Horton ES. Pre exercise feeding does not affect endurance cycle exercise but attenuates post-exercise starvation-like response. Med $\mathrm{Sci}$ Sports Exerc 1991; 23: 818-24.

24 Keller K, Schwarzkopf A. Preexercise snacks may decrease exercise performance. Physician and Sportsmedicine 1984; 12: 89-91.

25 Hasson SM, Barnes WS. Blood glucose levels during rest and exercise: influence of fructose and glucose ingestion. I Sports Med 1987; 27: 326-32.

26 Ahlborg G, Bjorkman O. Carbohydrate utilization by exercising muscle following preexercise glucose ingestion. Clin Physiol 1987; 7: 181-95.

27 Ahlborg G, Felig P. Influence of glucose ingestion on fuel-hormone response during prolonged exercise. I Appl Physiol 1976; 41: 683-8.

28 Koivisto VA, Harkonen M, Karonen SL, Groop HP et al. Glycogen depletion during prolonged exercise: influence of glucose, fructose, or placebo. J Appl Physiol 1985; 58: 731-7.

29 Felig P, Cherif A, Minagawa A, Wahren J. Hypoglycemia during prolonged exercise in normal men. N Engl J Med 1982; 306: 895-900.

30 Coyle EF, Hagberg JM, Hurley BF, Martin WH, Ehsani AA, Holloszy JO. Carbohydrate feeding during prolonged strenuous exercise can delay fatigue. J Appl Physiol 1983; 55: 230-5.

31 Bjorkman O, Shalin K, Hagenfeldt L, Wahren J. Influence of glucose and fructose ingestion on the capacity for long-term exercise in well-trained men. Clin Physiol 1984; 4: 483-94.

32 Coyle EF, Coggan AR, Hammert MK, Ivy JL. Muscle glycogen utilization during prolonged strenuous exercise when fed carbohydrate. J Appl Physiol 1986; 61: 165-72.

33 Williams C, Nute MLG, Broadbank L, Vinall S. Influence of fluid intake on endurance running performance. A comparison between water, glucose and fructose solutions. Eur J Appl Physiol 1990; 60: 112-19.

34 Rehrer NJ, Janssen GME, Brouns F, Saris WHM. Fluid intake and gastrointestinal problems in runners competing in a $25 \mathrm{~km}$ race and a marathon. Int J Sports Med 1989; 10 (Suppl.1): S22-S25. 